\title{
Symbolic politics, legalism and implementation: the case of street vendors in India
}

Commonwealth Journal of Local Governance

Issue 18: December 2015

http://epress.lib.uts.edu.au/ojs/index.php/cjlg

\section{Philip Amis}

International Development Department

University of Birmingham

Birmingham, UK

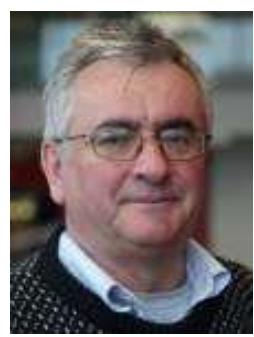

\begin{abstract}
This paper is concerned with attempts to manage street vendors in India. Firstly it traces the evolution of attempts at management, through guidelines introduced in 2002, to the 2014 Act which is legally enforceable. The act has not yet been implemented but the State of Madhya Pradesh has implemented its own act which is almost identical. This has been successfully implemented at an administrative level but on the ground nothing has changed. It is suggested that this reflects the importance of symbolic politics and problems of implementation.
\end{abstract}

\section{Introduction}

Managing the informal sector is one of the major challenges facing urban and local governments in the global South. The aim of this paper is firstly to highlight an innovative case study in this area India's policy for street vendors - describing the process through which the policy was formulated, and considering its implementation experience to date. The paper then discusses the politics of policy implementation in India more generally, including the tendency for progressive legislation to have regressive outcomes. Finally the paper reflects on the lessons for local government in the global South, in terms of managing street vendors and the informal sector.

This paper is based on an Urban Knowledge Network Asia (UKNA) research fellowship awarded to the author, and visit to India facilitated by the Centre for Environmental Planning and Technology University (CEPT), Ahmedabad, India between 25 March and 24 April 2014. The core area of the

(C) 2015 Philip Amis. This is an Open Access article distributed under the terms of the Creative Commons Attribution 4.0 Unported (CC BY 4.0) License (https://creativecommons.org/licenses/by/4.0/), allowing third parties to copy and redistribute the material in any medium or format and to remix, transform, and build upon the material for any purpose, even commercially, provided the original work is properly cited and states its license.

Citation: Commonwealth Journal of Local Governance 2015, 18: 4841, - http://dx.doi.org/10.5130/cjlg.v0i18.4841 
research was defined in the title of the project: Citizenship and informality: examining innovative state-led approaches and their impact on urban citizenship. This research was carried out through a review of (mainly grey) literature, fieldwork in Ahmedabad and Bhopal, and key informant interviews with relevant government officials and NGOs in Delhi, Bhopal and Ahmedabad. ${ }^{1}$

In the case of street vendors, India passed innovative policy guidelines in 2004, which were amended in 2009, and a national law was passed in March 2014. The distinction between a national guideline and a national law is significant in affecting how a policy may be implemented. This paper aims to evaluate the impact of the legislation and also to consider the general case of the relationship between municipal government and street vendors.

\section{The process of policy reform and legislation}

At this stage it is appropriate to describe how the Street Vendors (Protection of Livelihoods and Regulation of Street Vending) Act 2014 was achieved (Government of India 2014). Street vending has been highlighted as a policy issue in India since a 1985 ruling by the Bombay High Court in the case Bombay Hawkers Union v Bombay Municipal Corporation, which sought to legitimise street vendors through licensing, and creating hawking and non-hawking zones.

The ruling supported the vendors' right to trade and determined that the municipal corporation should find space for them to trade. This and subsequent Supreme Court rulings were significant in giving the vendors some political legitimacy and rights. In the original dispute in Bombay the municipal corporation estimated that there were 75,000 street vendors, while the National Association of Street Vendors of India (NASVI) estimated there were around 300,000. This discrepancy between official estimates of vendor numbers and those by vendor and civil society organizations is a perennial issue and clearly has significant relevance to the number of sites needed for vending. However the problem of the availability of appropriate sites to trade was not addressed by the ruling. To some commentators this issue remains the central problem faced by street vendors, especially in urban areas where space and land - especially in central locations - has a very high value.

In 2004 the Indian government drew up guidelines to improve the management of street vending. The centrepiece of these guidelines was the idea of Town Vending Committees (TVCs) tasked with determining where trading could or could not take place. TVCs were to be a partnership between vendors and the relevant municipal government, although their precise composition was unspecified. Nevertheless, TVCs were one of the first government attempts to manage street vending, and as such

\footnotetext{
${ }^{1}$ I should like to thank CEPT for hosting me in Ahmedabad, Atanu Chatterjee for help in interviewing in Ahmedabad and Richard Slater for general assistance in Bhopal.
} 
were an important global innovation. Previous work by the author note a few other examples of local mediated processes that have sought to 'manage' this sector (Amis 2004). However the main weakness of the 2004 policy statement was that it was only a guideline, and there was no process to compel state and municipal governments to implement it.

The result was patchy implementation: in only seven of India's 28 states, and with varying levels of commitment. Of these states, Madhya Pradesh (MP) is one of the most advanced. Some urban areas within states have also implemented the policy guidelines, with Bhubaneswar in Odisha highlighted as an exemplar (Sinha and Roever 2011).

The 2004 guidelines were updated in 2009, including modifications to improve implementation (Government of India 2009). Subsequent lobbying campaigns then attempted to get legislation passed to support street vendors, which could be enforced.

Street vendors have their own national organisation, the National Association of Street Vendors of India (NASVI). Founded in 1998, NASVI acts to create a supportive environment for street vendors, lobbies on their behalf, is involved in policy dialogue and seeks to build its capacity as a membership organisation. NASVI has been a crucial player in promoting the enabling regulatory framework for street vendors.

After the revised 2009 guidelines were published, the cause of street vendors was taken up by the National Advisory Committee, a non-governmental committee set up by Sonia Gandhi which might be classified as a grouping of 'the great and the good'. This was an ad hoc committee established to advise the government on potential areas of concern. The end result of this advisory process was a Supreme Court ruling that allowed national government policy to have an input into laws and practice at the municipal level - something not previously provided for in the Indian constitution and its various schedules of responsibilities.

India is basically a three-tier federal state. The top tier is the Government of India, sometimes called the 'union' level. The next tier is composed of 28 states, which operate a federal system, and the third tier is the municipal and/or local government. The states have extensive powers and there is a large research industry devoted to state comparative analysis, especially on social and economic policy.

Following the Supreme Court ruling it became possible for the union level to prescribe policies at the local government level. In the case of street vendors, it was proposed to pass a law that would considerably reinforce the 2004 and 2009 guidelines by providing a legal framework mandating their implementation, and overcoming the previous weakness that implementation had been at the discretion of individual states. 
The street vendors' law was finally ratified as the Street Vendors (Protection of Livelihoods and Regulation of Street Vending) Act 2014, with the drafting partly supported by the UK's Department for International Development. The drafting process involved extensive dialogue between NASVI and the Ministry of Housing and Urban Poverty Alleviation. At one point in 2013/14 the drafting process stalled, and to force progress NASVI organised a hunger strike. When it was finally tabled in 2013/14, the Act was passed unanimously by both houses of the India Parliament (Lok Sabha and Raja Sabha). The support was political, in that members of both houses realised that this was an issue that directly affected their potential support and/or political bases. The 2014 Act was widely seen as a major success for NASVI - which after nearly ten years of lobbying was actively involved in drafting the legislation - and also as a good example of partnership between government and civil society in policy-making. The Act also represents a potentially significant innovation in mechanisms to regulate the informal sector in the global South.

The key beneficial innovations of the Act are as follows:

- Codification of the idea of 'natural markets' - ie "a market where sellers and buyers have traditionally congregated for sale and purchase of products... [which] has been determined by the local authority on the recommendations of the Town Vending Development committee" (Section 2 (e)). This was an important innovative definition.

- Measures to ensure balanced membership of Town Vending Committees, which must include "members nominated to represent the non-governmental organisations... [and CBOs who] shall be not be less than ten per cent" (Section 22 (c)) and "the number representing the street vendors shall not be less than forty per cent who shall be elected by the street vendors in such manner as may be prescribed" (Section 22 (d)). This means that street vendors or stakeholders supportive of them comprise at least $50 \%$ of the committee and cannot be "run roughshod over by the municipality". ${ }^{2}$ This was important in empowering street vendors in the process of urban planning and/or politics.

- The zoning of areas to allow or prohibit vending. This is one of the key areas of the Act, widely referred to by government and interested parties as the 'traffic light system', although the legislation does not use this language. In this system, red is used for areas where vending is prohibited, green for areas where it is fully allowed, and amber for those where vending is allowed at certain times (Section 21 and First Schedule, 2 (c)).

\footnotetext{
${ }^{2}$ Personal communication Indian Government official April 2014.
} 
The Act also contains provisions to prevent harassment of vendors by the police and other agencies: "Notwithstanding anything contained in any other law... no street vendor who carries on the street vending activities in accordance with the terms and conditions of his certificate of vending shall be prevented from exercising such rights by any person or police..." (Section 27, Government of India, 2014).

In theory Section 27 should give street vendors considerable protection, but commentators note that this clause, which effectively overrules provisions elsewhere in the legal system, has not yet been challenged and implemented. The extent to which new provisions in India's legal system are implemented is often determined by the results of legal challenges and higher court rulings. As the street vendors' Act is still very new, the results of such potential challenges are as yet unknown.

In summary, the 2014 Act represents a major attempt to provide a progressive legal solution to the 'problem' of street vendors (and to some extent other sections of the informal sector). It is a unique innovation in urban governance within the global South. However, the key challenge lies in its implementation, discussed in the next section.

\section{Implementation experience}

While it is not yet possible to fully evaluate the 2014 Act, it is possible to assess experience in the state of Madhya Pradesh (MP), which effectively has been piloting the 2014 legislation. As noted earlier, MP was the state that most systematically implemented the 2004 and 2009 guidelines and, in broad policy terms, the guidelines and the Act are similar. This study found that officials in MP were clearly proud they were effectively leading the way in the implementation of the 2014 Act.

In implementing the guidelines, MP drew up its own legislation, so their current Act is the Madhya Pradesh Path Par Vikray Karne Walo Ki Jivika Ka Sanrakshan Aur Vikray Ka Viniyaman Adhiniyam 2012. At the time of writing, the 2014 Act was only just on the statute book. The only difference between the MP legislation and the 2014 Act is the composition of the TVCs, as in MP there is only provision for $40 \%$ of TVC members to represent street vendor interests, compared to 50\% in the 2014 Act. Nevertheless MP has tried to implement the 2014 Act more seriously and comprehensively than any other state in India. Reasons advanced for this by respondents were on the one hand the degree of institutional autonomy that local government in MP enjoys, and on the other hand the fact that, as a poor (or 'backward') state, it is sensitive to popular opinion and/or poorer citizens' votes.

Views on implementation of the 2014 Act in MP vary. There does exist a systematic process through which zones in urban MP, including Bhopal, have been divided into red, amber and green (ie those where trading is prohibited, time-bound, or freely allowed). The zoning is in narrative rather than 
mapped form, using statements such as "next door to the number $X$ bus stop at $Y$ location". This zoning is well documented in Bhopal and across the state. A consultant working in the field noted that "they" [the Bhopal local government] had followed the 2012 Act to "the letter of the tee". It was not possible to establish the rationale for definition of the zones, but traffic use appears to have played a part. Discussions with Bhopal Municipal Corporation (BMC) indicated that there was no physical planning map that showed the zones.

However, some concerns were voiced that the zoning process was more top-down than the Act intends. NIDAM, an NGO in MP that lobbies for the informal sector in general and street vendors in particular, and is a local member of NASVI, was one organisation to voice such concerns. The representative of NIDAM interviewed for this study had not seen a map of vending zones either, but thought that "there might be one". ${ }^{3}$ Given that street vendors' activity often involves spatial planning on a micro scale this seems an important concern. It seems strange that, if such a map exists, the researcher was not able to access it during discussions with BMC. The lack of a map may also indicate that management of street vendors was seen as a general administrative issue rather than a planning issue. This is in contrast to some states, such as Gujurat, where the control of street vendors' activities is part of the process of development control.

The view of NIDAM and of vendors at the sites visited for this study was somewhat different from BMC. First, they were actively involved with working with and sometimes challenging BMC. The relatively strong influence of civil society and the various levels of government was highlighted, and respondents' desire for vendors and government representatives - as far as possible - to work together was noteworthy. They acknowledged that Bhopal's urban public spaces had been defined according to the three categories of green, amber and red, and they had the same 'narrative' planning documents as the BMC, but they expressed major concerns about what these meant on the ground. There was also a dispute over the number of street traders in Bhopal, with NIDAM claiming two or three times more vendors than the BMC estimate. This mirrored earlier disputes in Mumbai and seems to be a common issue in street vending (Shapiro Anjaria 2006). NIDAM also highlighted a dispute with BMC over ID cards. NIDAM was lobbying for licences, which have a stronger legal backing, but BMC was issuing ID cards instead. NIDAM also claimed that of the 5,000 licences issued, 1,500 went to individuals who were not street vendors but were connected to BMC through patronage networks. It was not clear what the advantage of a licence would be, but the licence was seen a potential opportunity for those who could obtain one.

\footnotetext{
${ }^{3}$ It was suggested to me at a workshop at DPU, University College London in October 2015 that this ambiguity might be intentional and gives a degree of flexibility for political purposes.
} 
The first complaint about the 'traffic light' zoning was that the green zones often did not exist, or were in unsuitable locations, either because there was insufficient footfall to create a market, or because the environmental conditions were unsuitable for trading. Of the 46 locations zoned green in the BMC survey, the vendors claimed that only four were acceptable. After a more detailed discussion - covering every listed site - it appeared that about 30 sites were suitable for trading. The unsuitability of designated trading zones is a frequent complaint in the street vending debate in India (Bhowmik 2003, p. 1544).

An even more illuminating discussion concerned the red zones (where trading was prohibited). At one point the NIDAM official commented that vendors were "trading in all the red zones". The researcher was urged to visit a site "100 metres from BMC HQ where approximately 100 vendors are actively working or trading". It was strongly suggested that vendors could trade with impunity when they or their representatives had "political connections", suggesting that despite the impressive legal framework, patronage politics was still very much alive. Indeed, at these sites vendors were expected to pay 10-20 Rupees a day to the council. Although the precise legal status of this payment was unclear, it appeared to be accepted as a common or expedient practice. Intriguingly, the impression from the interviews was that the amber zone was the one most successfully and meaningfully implemented, possibly because it is the least politically problematic.

Evictions were also seen as problematic. It appeared that evictions were more likely at the politically insignificant geographical edge of the urban area. In addition it was noted that evictions were more likely at the end of the financial year when officials sought to meet various 'targets' - and probably less likely around the time of national or state elections.

It was interesting to note that NIDAM had been able to use India's Right to Information Act (the equivalent of a Freedom of Information Act) to successfully challenge the fees levied on those trading in red zones. They successfully argued that if a vendor should not be trading there, he or she should not be paying a fee. The case raises interesting issues about NIDAM's priorities and perspective There is quite a lot of evidence, including from practice observed in BMC, that large and/or successful street vendors are advantaged at the expense of smaller vendors. This is a recurring theme in India and suggests that the street vendor lobby is somewhat internally contested. Indeed some members cannot really be described as 'urban poor'; the larger or more established vendors would be more accurately described as the lower end of the formal retail sector. Furthermore, they are able to gain political traction as they are what in Victorian terms might be described as the 'deserving poor'. This author has elsewhere noted the widespread use of categories of deserving and undeserving poor in Indian policy-making and in attitudes to the urban poor (Amis 2001). 


\section{Impact of the Act}

No definitive conclusions can be drawn, given the limited nature of this research. Nevertheless, the following seem appropriate observations. First, almost all commentators agreed that the law was an improvement on the previous situation and gave some protection to street vendors. In this sense it is a reform in the right direction. Secondly, there is a mismatch between the policy on paper (ie listed zones) and its implementation on the ground. Thus the red, amber and green zones do not actually determine trading. A few caveats are appropriate. First, the policy is still in its early stages and the listing of zones could be a first step, to be followed by enforcement. Second, the fieldwork was done just before and during national and state elections in 2014; as indicated above, it is very unlikely that at such a time any municipality would take steps which might alienate voters.

In some cases it appears that the red, amber and green zones were almost a proxy for identifying prime sites. It is not yet clear whether implementation of the 2014 Act is likely to strengthen or weaken the spatial inequalities that flow from the workings of the urban land market. These inequalities are important in the public space that street vendors seek to occupy, and the importance of public space in the livelihoods of street vendors has been well documented elsewhere (Brown 2006).

\section{Reflections on the politics of implementation in India Some thoughts on Indian policy-making}

At this stage it is appropriate to note some specific aspects of Indian policy-making that will help in understanding street vending policy.

The overarching observation is that India is highly opaque in terms of policy formulation and implementation. Three elements of the policy process are particularly extreme: symbolic policymaking; legalism; and the problems of implementation. It is crucial to understand these factors, as they give Indian policy-making specific characteristics.

\section{Symbolic policy-making by politicians}

Symbolic policy-making encapsulates the idea that politicians, and to a lesser extent officials, have to be seen to do something. To a great extent this is driven by the nature of Indian democracy - the electoral turnout of poor or lower income groups is usually higher than that of higher income groups (Kohli 2012). Despite the recent resurgence of the ruling BJP (Bharatiya Janata Party) and its free market agenda, welfare and socialist thinking is still widespread. Although there is now a debate about the scale of India's 'welfare state', the role of the state is still strongly influenced by the interventionism of the 1940s and 1950s. The Government of India, and to a large extent the general public, expects a high level of intervention from the state, further complicated by the complexity of identity politics in India. 
At its simplest, while many in the global South expect little from the state, the Indian body politic expects a lot. This paper posits that this creates greater pressure on politicians to a) do something and b) be seen to do something - mainly popular and/or poverty-alleviating schemes (Dreze and Sen 2013). Clearly, this situation is likely to lead to symbolic political initiatives.

\section{Reliance on the legal system to resolve social and political disputes}

It is difficult to overstate the importance of the legal system in Indian policy-making. In the world of street vending almost all reforms appear to have been driven by court rulings. Many of the reforms, guidelines and laws appear to start from the 1985 Bombay Hawkers Union v Bombay Municipal Corporation ruling, which outlined a scheme for licensing street vendors. Unfortunately the number of street vendors in each location does not appear to have been specified. The result - at least according to some sources - was a huge demand for licences. Many subsequent initiatives seem to return to this issue: that hawkers' or vendors' zones can be declared, but the number of vendors at each site remains problematic, which influences how the zone is policed or administered.

This issue is made more complex by the provisions of the Indian constitution, with some responsibilities defined as at union level, some at state level and some at local level. In some cases this is helpful, but in other situations it may not be clear where responsibility lies. The NASVI example discussed above is a useful snapshot: here, NASVI sought and obtained a special ruling to allow national legislation to be made for street vendors, but in other circumstances vending might be seen as a state or local function, rather than a national issue.

More generally, Indian policy often seems to go through a process of legislation being passed and then challenged in the courts, often resulting in a ruling that causes an impasse, or the legislation being weakened and in some cases effectively disabled. There are some indications that this might happen to the 2014 Act on street vendors. It is certainly evident that NASVI put a great deal of trust in the power of the legal system, as their efforts, campaigning and enthusiasm for the 2014 law demonstrate.

Much Indian policy-making appears to end up in the legal system, such that the legal system and its rulings become a major player in the implementation of policy and in resolving political and legal disputes. It then becomes a moot point whether the legal system is effectively implementing policy, or stopping policy being implemented.

A few points are worth making. Firstly, there seems in India to be always a tendency to increase the amount of legislation. Secondly, in India, as in most countries, surprisingly few policies are ever formally discontinued, which means they often linger in some form. The result is a corpus of often 
conflicting legislation, which increases the significance of court rulings for policy development and implementation. It also means that policies are not definitive, as they are open to further legal challenge, which increases uncertainty for everyone.

\section{Problems of implementation}

Implementation has been identified as a potential weak aspect of the policy-making process in many countries. In India outcomes are even more uncertain as the detail of policy may be effectively determined at local level. There is a well-publicised literature about street-level bureaucrats, and Lipsky (1980) for example argues that administrative requirements and regulations are often so complex that they are effectively unworkable. The result is that street-level bureaucrats (local officials) effectively redesign the original guidelines to simpler versions which they are able to work with. This approach is clearly relevant to the Indian context.

Two points flow from this analysis. First, street vendor policy in India (encapsulated in the 2004 and 2009 guidelines and the 2014 Act) is an example of how the process of implementation is altered at local level. This approach contrasts with a 'command and control' model which gives no agency to officials actually implementing a policy. In many cases implementation raises issues that cannot be predetermined and can only be solved on the ground. Second, the way that policy is changed through implementation may or may not be neutral in terms of the original policy objective.

In this context, a NASVI official's comments about NASVI's future role, given that it has achieved its campaign objective of passing an enforceable law, was illuminating. NASVI now plans to focus on implementation: "We will be a watchdog ... there are loads of legal provisions which are not properly implemented [eg the provision that a TVC must have a $40 \%$ committee membership representing vendors] ... the problem is they [the government] will do the street vendor survey but corruption is so high in India that [the vendor representatives] will be those who pay them." NSAVI also noted that it would have to watch "how they will define natural markets". The group evidently feels that all major aspects of the 2014 Act will need to be actively monitored in practice. Similar approaches can be widely seen in the complex Indian government system, where many actors are quite experienced in manipulating processes to their advantage. The identity nature of much of Indian policy and politics is relevant here, as such bodies are - compared to many countries - experienced in dealing with this complexity and diversity.

The important questions here are whether corruption of the policy implementation process is malevolent or simply incompetent, and whether failure to implement policies represents a systematic bias. This study has not gathered sufficient evidence to make a strong statement on this, but this 
author's tentative conclusion is that Indian policy-making is often characterised by a tradition of progressive legislation being modified often resulting in regressive outcomes. ${ }^{4}$

First, there is some evidence of a particularisation of government schemes. It seems that some progressive states in India can implement progressive national policies, while others cannot or do not (Kohli 2012; Dreze and Sen 2013). Indeed some states which might be described as "neopatrimonial" - including MP - are criticised for a lack of "public purpose" (Kohli 2012, p. 153) Second, policy implementation is likely to reflect the prevailing political economy, class and caste composition of each state and location. Finally, there is quite extensive academic evidence in India that middle-class groups have often been the most successful users of participatory approaches which are designed to empower the poor, but often end up promoting middle-class interests (Shapiro Anjaria 2006).

It is not clear how these processes work, but they are powerful forces capable of redefining 'progressive' legislation, as seen above. The extent to which this power varies by state, political economy and administrative capacity is also unknown.

\section{Lessons on managing the informal sector for local government in the global South}

The key lesson of the Indian experience is that a rights-based approach is not sufficient to protect poorer citizens and informal economies. Effecting change is not just about providing the appropriate legal frameworks (although it should also be noted that, compared to many countries of the global South, India has a robust legal system, an active civil society and a free press). The rights-based approach goes quite a long way towards strengthening the status of the working poor, but it needs political consensus to support and reinforce it. A change in official culture and attitudes towards the informal sector is also needed. Clearly legal provisions are an important step in the right direction, but they are not the end game. Nevertheless, in trying to design policies for the informal sector, legal changes are a very helpful entry point. The Indian example discussed in this paper shows how, despite their limitations, they are important in bringing into the mainstream citizens who may previously not have been seen as legitimate actors and/or members of society with rights and entitlements.

\footnotetext{
${ }^{4}$ I explored this thesis with Odisha officials (IAS) at a policy workshop at Somerville College in Oxford in Jan 2015. This is one of the states that had most implemented the 2009 guidelines and in some cases was seen as an exemplar. Some disagreed with this analysis but a significant group - often in private - did say to me that they supported this interpretation of events and policy making. Furthermore some agreed with the result or outcomes but admitted they did not understand the process.
} 


\section{References}

Amis, P. (2001) Rethinking UK aid: Lessons from an impact assessment study of DFIDs slum improvement projects. Environment and Urbanization, 13 (1), 101-103. doi: http://dx.doi.org/10.1177/095624780101300108

Amis, P. (2004) Regulating the informal sector: Voice and bad governance. In: Devas, N. with Amis, P., Beall, J., Grant, U., Mitlin, D., Nunan, F. and Rakodi, C. (2004) Urban governance, voice and poverty in the developing world. London: Earthscan. pp. 145-163.

Bhowmik, S. (2003) National policy for street vendors. Economic and Political Weekly, April $19^{\text {th }} 2003$.

Brown, A. (ed) (2006) Contested space; street trading, public space and livelihoods in developing cities. Rugby: ITMG Publishing. doi: http://dx.doi.org/10.3362/9781780444703

Dreze, J. and Sen, A. (2013) An uncertain glory: India and its contradictions. London: Allen Lane.

Government of India. (2009) National policy on street vendors. New Delhi: Ministry of Housing and Poverty Alleviation.

Government of India. (2014) The Street Vendors (Protection of Livelihoods and Regulation of Street Vending) Act 2014 (7of 2014) New Delhi: Universal Law Publishing. Available at: http://www.indiacode.nic.in/acts2014/7\%20of\%202014.pdf

Kohli, A. (2012) Poverty amid plenty in the new India. Cambridge: Cambridge University Press. doi: http://dx.doi.org/10.1017/CBO9781139015080

Lipsky, M. (1980) Street level bureaucracy. New York: Russell Sage Foundation.

Shapiro Anjaria, J. (2006) Street hawkers and public space in Mumbai. Economic and Political Weekly, 41 (21), 2140-2146.

Sinha, S. and Roever, S. (2011) India's national policy on urban street vendors. WIEGO Policy Brief 2. Manchester, UK: Women in Informal Employment Globalizing and Organizing. 